INNOVATIONS IN PRIMARY CARE

\title{
Fulfilling a Need: A Residency-Based Program to Preserve a Suboxone Treatment Program in a Rural Community
}

\author{
Meredith C. Buck, $M D^{1}$ \\ Ali N. McCormick, DO' \\ Mollie M. Meagher, $D^{1}$ \\ Glenn Kauppila, $\mathrm{DO}^{2}$ \\ Terrence J. Witt, $M D^{1}$ \\ 'Mayo Clinic Family Medicine Residency-Eau Claire, Eau Claire, \\ Wisconsin \\ ${ }^{2}$ Mayo Clinic Health System-NW WI, Eau Claire, Wisconsin \\ Ann Fam Med 2021;19:561. https://doi.org/10.1370/afm.2718.
}

\section{THE INNOVATION}

To respond to an urgent community and educational need, we rapidly created a medication-assisted treatment program for opioid use disorder within our family medicine residency practice. We did this by transitioning a large group of established patients from a single family physician (G.K.) who was departing the community to obtain further training.

\section{WHO \& WHERE}

Mayo Clinic Family Medicine Residency-Eau Claire is located in a town of 70,000 people and also serves numerous smaller surrounding communities in rural Wisconsin. The departing provider was practicing with the same health system in the same community. The 2 practices share 1 electronic health record.

\section{HOW}

As with many rural communities, patient access to addiction medicine services, including Suboxone, is extremely limited in our area. Transitioning these patients into multiple practices was likely to be difficult and would increase the risk of interruption of their treatment and relapse. The project developed because of resident and faculty interest in fulfilling an urgent community need. Our primary goals were to quickly initiate a medication-assisted treatment program, preserve clinician satisfaction, and enhance resident addiction medicine education.

Conflicts of interest: autbors report none.

\section{Corresponding author}

Meredith C. Buck

Mayo Clinic Family Medicine Residency-Eau Claire

1400 Bellinger St

Eau Claire, WI 54703

meredithbuck8@gmail.com
A faculty member became aware of the community physician's anticipated departure and his limited success in early attempts to identify clinicians to continue care. We then formed a multidisciplinary team of 3 resident champions, the faculty member, and the departing clinician. This team developed an implementation process to facilitate the rapid transition of patients into our practice. It involved the development of didactic sessions and documentation templates which facilitated treatment. A process was developed to allow seamless scheduling with our residency clinicians. All eligible resident and faculty clinicians attained their Drug Enforcement Administration waiver to prescribe Suboxone using an online course. Virtual patient visits were utilized when appropriate. We also began accepting new patients desiring, and appropriate for, medication-assisted treatment. Clinicians were surveyed regarding perceived barriers and general impressions before and 4 months after initiating the process.

All but 1 patient transitioned their management to our residency practice during the first 4-month period (32 of 33 patients). The vast majority of these patients had been utilizing Suboxone for 1-5 years and demonstrated to us through their stories the benefits of medication-assisted treatment and how it stabilized and ultimately improved their lives. We also added 4 new patients during this process. Almost all residents and all faculty had positive impressions of the process and most agreed they would continue to practice medication-assisted treatment in their future practices.

\section{LEARNING}

Patients and their original physician avoided the challenges of identifying other clinicians and possibly being unable to access care. We feel this significantly decreased the risk of relapse with its associated costs to the individuals and community. Our residency program engaged the community and found opportunities to move beyond the constraints of usual residency practice to implement this addiction service project. We found in the process that doing so can have numerous benefits for patient care, community health, and clinician education and satisfaction.

To read or post commentaries in response to this article, go to https://www.AnnFamMed.org/content/19/6/561/tab-e-letters.

Key words: medication assisted treatment; opioid use disorder; buprenorphine/naloxone; Suboxone; family medicine residency; rural health care

Submitted December 22, 2020; submitted, revised, March 7, 2021; accepted March 18, 2021. 